Int. J. Electrochem. Sci., 14 (2019) 1197 - 1207

International Journal of

ELECTROCHEMICAL

SCIENCE

WWW.electrochemsci.org

\title{
Effects of Negative Electrodes Coated by ZnO with Different Morphologies on Electrochemical Performances and Safety of Lithium Ion Batteries
}

\author{
Chia-Ming Chang ${ }^{1,3}$, Hsiu-Fen Lin ${ }^{2, *}$, Shih-Chieh Liao ${ }^{1}$,Hsin-Tien Chiu', \\ Chia-Erh Liu ${ }^{1}$ and Han-Lin Guo ${ }^{2}$ \\ ${ }^{1}$ Department of Nanomaterials for Energy Storage, Material \& Chemical Research Laboratory, \\ Industrial Technology Research Institute, Hsinchu 31040, Taiwan \\ ${ }^{2}$ Department of Materials Science and Engineering, National Formosa University, Yunlin 64054, \\ Taiwan \\ ${ }^{3}$ Degree Program of Science, National Chiao Tung University, Hsinchu 30010, Taiwan \\ *E-mail: tiffany1030@nfu.edu.tw
}

doi: $10.20964 / 2019.02 .49$

Received: 6 October 2018 / Accepted: 21 November 2018 / Published: 5 January 2019

To improve the safety of lithium-ion batteries, this study applied topographically different $\mathrm{ZnO}$ to the surface of negative graphite electrodes to serve as heat-resistant layers and explored the effects of these layers on a battery's electrochemical and safety features. The results indicate that when using a tetrapod $\mathrm{ZnO}(\mathrm{T}-\mathrm{ZnO})$ particle coating as a heat-resistant layer on a negative graphite electrode, ion diffusion is improved because $\mathrm{T}-\mathrm{ZnO}$ has a three-dimensional network structure and forms highly porous layers. This causes batteries to retain excellent electrochemical characteristics even if they contain inactive substances. Moreover, the results of overcharge and penetration tests were satisfactory, suggesting that the batteries are highly safe.

Keywords: Tetrapod ZnO; Rod ZnO; Negative electrode; Electrochemistry; Safety; Thermal stability; Li-ion battery.

\section{$\underline{\text { FULL TEXT }}$}

(C) 2019 The Authors. Published by ESG (www.electrochemsci.org). This article is an open access article distributed under the terms and conditions of the Creative Commons Attribution license (http://creativecommons.org/licenses/by/4.0/). 